Comparison of the efficiency of exercise, electrical muscle stimulation, electromyographic biofeedback and robotic rehabilitation in tibialis anterior muscle activation of hemiplegic patients

\title{
Egzersiz, elektriksel kas stimülasyonu, elektromyografik biofeedback ve robotik rehabilitasyonun hemiplejik hastaların tibialis anterior kas aktivasyonu üzerine etkileri
}

\author{
Mustafa ALHADDAD ${ }^{1}$ (D) Sema POLAT ${ }^{2 @(D)}$ Emir İbrahim IŞIK ${ }^{3}$ (D) \\ ${ }^{1}$ Fizica Medical Center, 01170, Adana-Turkey \\ ${ }^{2}$ Cukurova University, Faculty of Medicine, Department of Anatomy, 01170, Adana-Turkey \\ ${ }^{3}$ Cukurova University, Abdi Sütcü Vocational School of Health Services, 01070, Adana-Turkey
}

Atıf gösterme/Cite this article as: Alhaddad M, Polat S, Işı Eİ. Comparison of the efficiency of exercise, electrical muscle stimulation, electromyographic biofeedback and robotic rehabilitation in tibialis anterior muscle activation of hemiplegic patients. ADYÜ Sağllk Bilimleri Derg. 2021;7(1):1-13. doi:10.30569.adiyamansaglik.799520

\begin{abstract}
Aim: The comparison of the efficiency of Classical Physical Therapy and Rehabilitation (CPTR), Electrical Muscle Stimulation (EMS), Electromyographic Biofeedback (EMG-BF) and Robotic Rehabilitation (RR) on tibialis anterior (mTA) muscle activation and functions of hemiplegic patients was aimed.

Materials and Methods: Thirty hemiplegic patients aged 40-86 years were participated. The range of motion (ROM), 10 meters walk test, Modified Ashworth Scale (MAS), strength measurements, and Visual Analog Scale (VAS) were performed.

Results: In the measurements including dorsi flexion ROM, EMG-BF, NMMT (right and left), a significant difference was found in all Groups. Also, the significant difference in dorsi flexion ROM was higher in Group 3 than Group 2 and Group 1. Additionally, the plantar flexion ROM was higher in Group 1 than Group 3 and Group 2.

Conclusion: There were the positive effects of three different treatment methods on ROM, walking time, spasticity and mTA muscle strength. Also, three treatment modalities contributed to recovery level of hemiplegic patients.
\end{abstract}

Keywords: Electromyographic Biofeedback; Hemiplegia; Classic Physical Therapy and Rehabilitation; Robotic Rehabilitation.

Yazışma Adresi/Address for Correspondence: Sema POLAT, Cukurova University, Faculty of Medicine, Department of Anatomy, 01170, Adana-Turkey, E-mail: sezaoz@hotmail.com

Gelis Tarihi/Received:24.09.2020 Kabul Tarihi/Accepted:11.12.2020

$\mathrm{Bu}$ eser, Creative Commons Atıf-GayriTicari 4.0 Uluslararası Lisansı ile lisanslanmıștır.

Telif Hakkı @ 2021 Adıyaman Üniversitesi Rektörlüğü
Öz

Amaç: Klasik Fizik Tedavi ve Rehabilitasyon (KFTR), Elektriksel Kas Stimülasyonu (EKS), Elektromyografik Biyofeedback (EMG-BF) ve Robotik Rehabilitasyon'un (RR) hemipleji hastalarının tibialis anterior kas (mTA) aktivitesi ve fonksiyonları üzerine etkinliğini karşılaştırma amaçlandı.

Gereç ve Yöntem: Yaşları 40-86 arasında değişen otuz hemiplejik hasta çalışmaya katıldı. Eklem hareket açıklığı (EHA), 10 metre yürüme testi, Modifiye Ashworth Skalası (MAS), kuvvetlendirme ölçümleri ve Görsel Analog Skalası (GAS) uygulandı.

Bulgular: Dorsi fleksiyon EHA, EMG-BF ve NMMT (sağ-sol) ölçümlerinde bütün gruplarda anlamlı farklılık bulundu. Dorsi fleksiyon EHA'da anlamlı farklılık Grup 3'te Grup 2 ve Grup 1'den daha yüksekti. Ayrıca, plantar fleksiyon EHA artışı ise Grup 1'de Grup 3 ve Grup 2'den daha yüksekti.

Sonuç: Uygulanan üç farklı tedavi metodunun EHA, yürüme zamanı, spastisite ve tibialis anterior kas kuvvetini içeren parametreler üzerine olumlu etkileri vardı. Ayrıca, üç tedavi yöntemi hemiplejik hastaların iyileşme düzeylerine katkı sağladı.

Anahtar Kelimeler: Elektromyografik Biyofeedback; Hemipleji; Klasik Fizik Tedavi ve Rehabilitasyon; Robotik Rehabilitasyon.

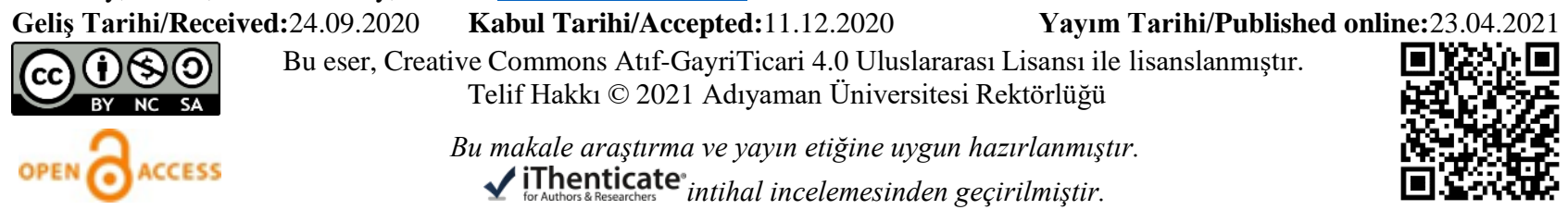




\section{Introduction}

There are many definitions about stroke. Description of stroke is accepted as acute happening of focal dysfunction of the brain, retina, or spinal cord taking more than one days or when imaging tecnique including CT/MRI or autopsy show central infarction or haemorrhage related to the symptoms. ${ }^{1}$ Stroke is the third most frequent reason of death all around the world. ${ }^{2,3}$ Approximately, in every 40 seconds a subject in the U.S. suffers a stroke. $^{3,4}$ Nearly, two thirds of stroke survivors have residual neurological deficits, this cause often to a sedentary lifestyle. ${ }^{3-5}$ The one of the main problem is hemiparetic gait and this leed to falls and fractures. ${ }^{3}$ Also, the other main disfunctions are especially mobility and stability of joints, muscle force, tone, endurance and reflexes, control of movement, gait pattern functions, and loss of proprioception. Those lead to problems with transferring, maintaining body position, mobility, balance, and walking. ${ }^{5-9}$ Moreover, stroke survivors can show many deficits, including hemiparesis /hemiplegia, spasticity and gait dysfunction. Hemiparesis caused by stroke effects activities of daily living and quality of life negatively. In particular, spasticity is the prominent clinical symptom following stroke. This affect $4 \%$ to $42.6 \%$ of subjects and the spasticity rate of incidence is between $2 \%$ to $13 \%$. The reason of the plantar flexor muscles'spasticity is reported as equinovarus foot deformity. The deformity can result from walking impairments in stroke subjects. ${ }^{10,11}$ Spasticity of the ankle plantar flexor leading to equinovarus foot deformity and foot invertors is major problem in subjects having stroke and may affects walking rehabilitation adversely. ${ }^{12,13}$ Also, it leads to dysfunction in structures and functions of skeletal muscle tissue, such as the development of contractures. ${ }^{7,8}$. Furthermore, increased knee flexion or excessive knee extension during walking is seen mostly for stroke patients. ${ }^{12,13}$. Many treatment methods are used in the stroke rehabilitation such as surgical, medical and physiotherapy techniques. ${ }^{14}$. The aims of physiotherapy techniques such as Bobath techniques, Neuromuscular Electrical
Stimulation (NMES), therapeutic exercises, streching, strength training, Robotic rehabilitation, and EMG Biofeedback (EMG$\mathrm{BF}$ ) used for the treatment of spasticity or stroke rehabilitation are to provide and help sensorimotor recovery. It leads to optimal independence in daily life activities. ${ }^{8,9,14-16}$ The electromyographic biofeedback (EMG$\mathrm{BF}$ ) is preferred for muscle relaxation treatment, coordination and more recruitment of motor units. ${ }^{8,9}$ However, there was no consensus on the effect of combined applications on spasticity in the tibialis anterior muscle (mTA).

In this context, the purpose of present study was to investigate the effects of three different treatment modalities including Classic Physical Therapy and Rehabilitation (CPTR); CPTR and Electrical Muscle Stimulation (EMS) with Robotic Rehabilitation (RR); and CPTR, EMS with EMG-BF on tibialis anterior muscle (mTA) activation and functions of stroke patients.

\section{Materials and Methods}

\section{The type of the research}

This research was an experimental study, which was conducted in Adana Private Fizica Medical Center.

\section{The samples of the research}

Firstly, the patient consent forms were signed by chronic stroke. Moreover, they were divided into three groups. The first group received 30 sessions of Classic Physical Therapy and Rehabilitation (CPTR), the second group received 30 sessions of CPTR and Electrical Muscle Stimulation (EMS) with 15 sessions of Robotic Rehabilitation (RR), and the third group received 30 sessions of CPTR and Electrical Muscle Stimulation (EMS) with 15 sessions of EMG-BF. The exercise practices taking 40 minutes including Bobath Neuro Developmental Treatment (NDT) was applied by the same physiotherapist (M.A.) to three groups on five times per week during one month. Additionally, 15 sessions Robotic Rehabilitation programme lasting 15 minutes and 30 sessions and 30 minutes Electrical Muscle Stimulation were applied to the 
second group. The practitioner applied robotic (Bama technology brand ROBO GAIT v1.1 model locomotor therapy system device having $140 \mathrm{~kg}$ in weight and $200 \mathrm{~cm}$ in height) rehabilitation for the lower extremity. Additionally, the EMG-BF practice which took 10 minutes each time adjunct to 30 minutes Electrical Muscle Stimulation were implemented to the third group on 15 times. EMG-BF (EMG biofeedback portable tool brand NeuroTrac ${ }^{\circledR}$ MYOPlus having 2 channel EMG as well as 4 channels of NMES, and 2 channel EMG triggered stimulation with stimulation on 4 channels (Figure 1-2).

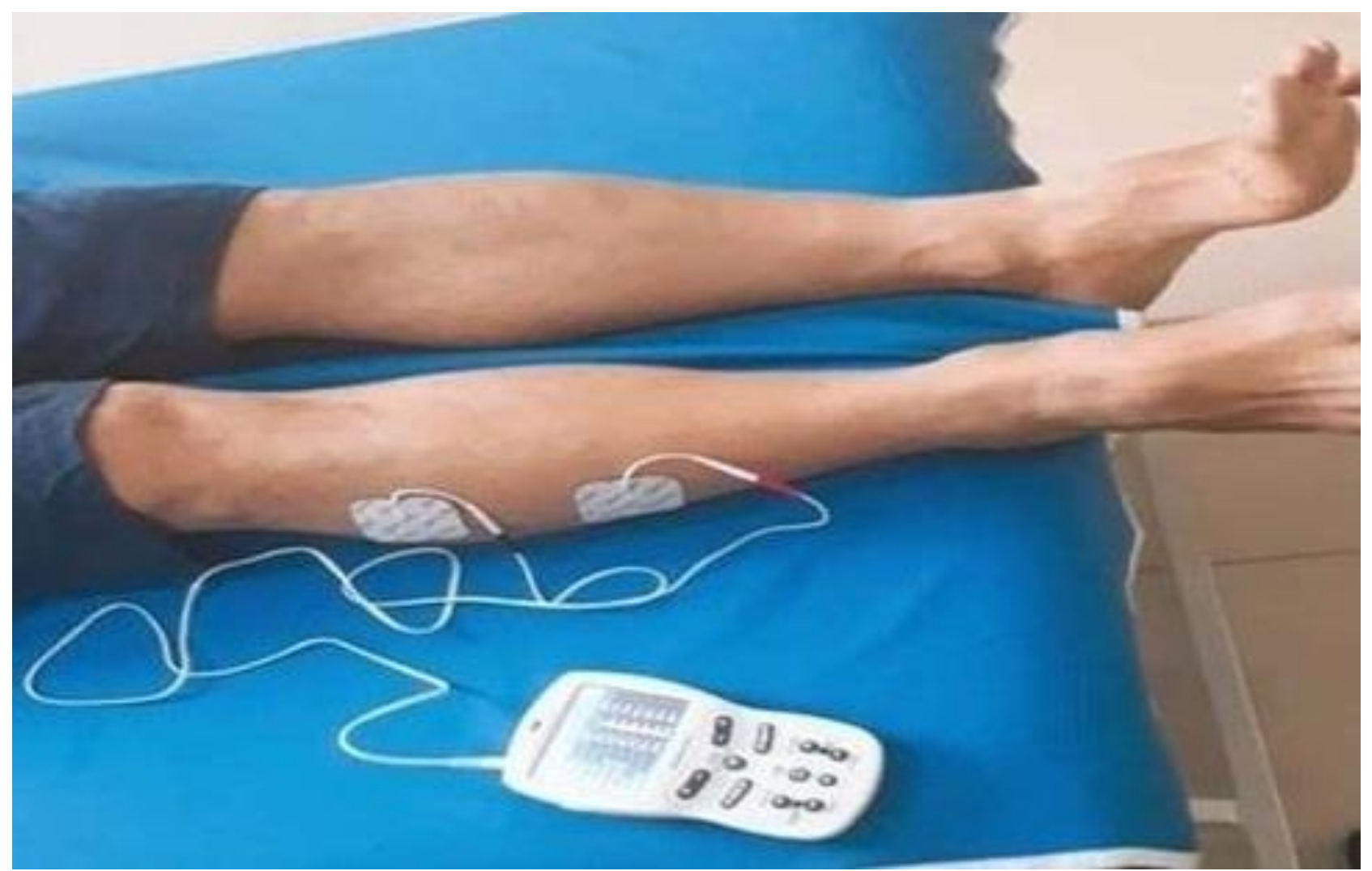

Figure 1. EMG-BF measurement.



Figure 2. Lower extremity robotic practice 


\section{Treatment protocol}

Group 1: Classical physical therapy and rehabilitation (40 minutes).

Group 2: Classical physical therapy and rehabilitation (40 minutes), Electrical muscle stimulation (30 minutes) and Robotic Rehabilitation (15 minutes).
Group 3: Classical physical therapy and rehabilitation (40 minutes), Electrical muscle stimulation (30 minutes) and Electromyographic Biofeedback (10 minutes).

Flow Chart of hemiplegia patients'treatment protocol was shown in Figure 3.

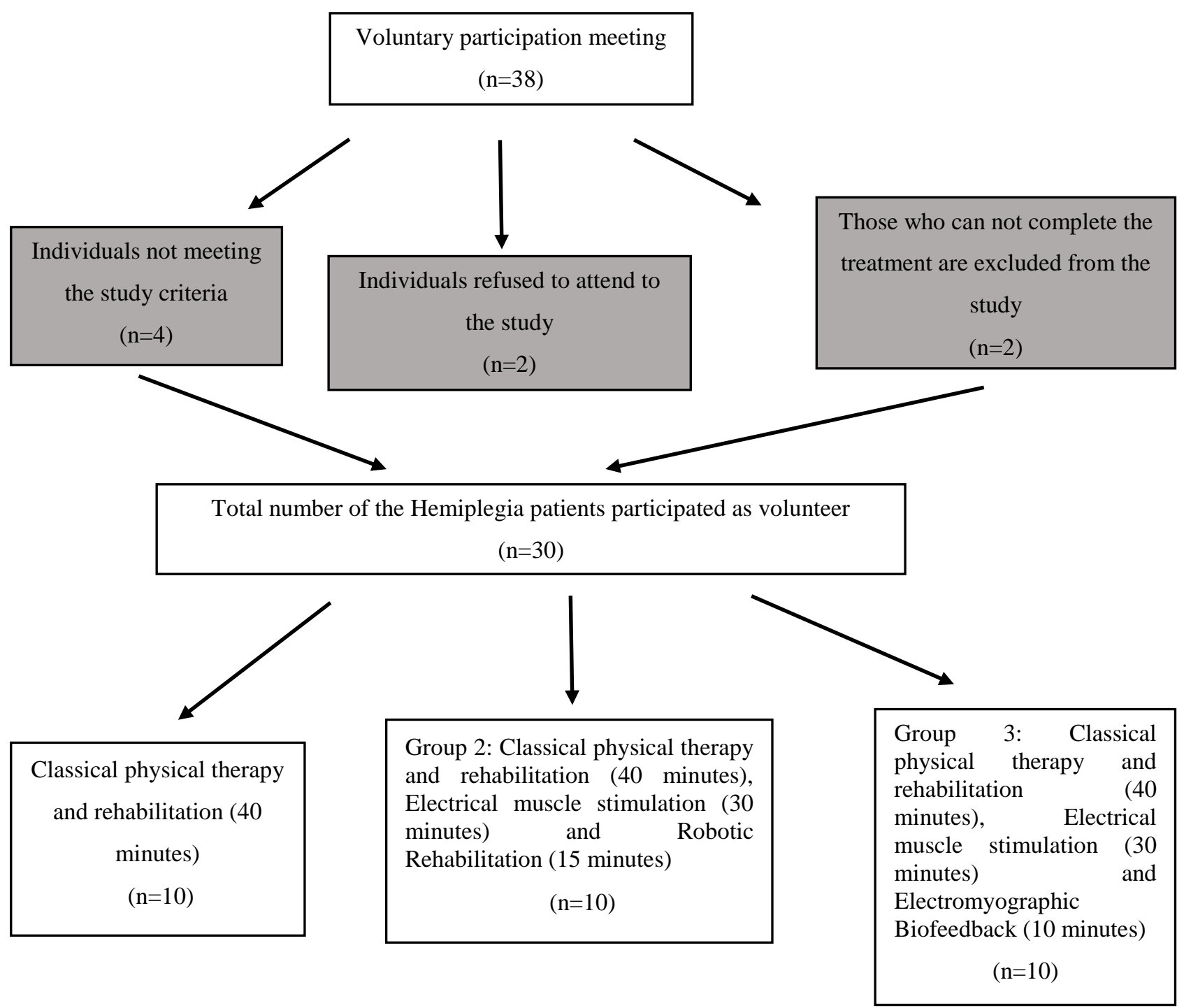

Figure 3. Flow chart of hemiplegia patients treatment protocol.

\section{Data collection tools}

\section{Classic physical therapy and rehabilitation programme (CRTR)}

30 sessions of Classic Physical Therapy and Rehabilitation (CPTR) programme was prepared by selecting from exercise and electrical stimulation practice on tibialis anterior muscle (mTA). Also, exercises were consisted of gait training, stretching exercises to agonist muscles, strengthening exercises to antagonist muscles and balance-coordination exercises. The exclusion criterias of the 30 hemiplegic patients were as follows:

- Patients having a stroke more than over a year ago.

- Transiscemia cases

- Patients with calcification of the ankle joints or who were at risk of deep vein thrombosis.

- Patients having spasticity degree $1+$ and above according to Modified Ashworth Scale; 
- Patients who did not participate to the study one week or over

Moreover, the design assessment including age, gender, height, weight, dominant side, sociodemographic features, ankle plantar and dorsi flexion ROM, 10meters walking test, MAS, VAS and Muscle strength (mTA) with Nicholas Manual Muscle Tester. All measurements were practiced twice to subjects and the best value was recorded. These tests were as follows:

Joint range of motion (ROM): Ankle joint plantar flexion and dorsiflexion ROM measurements were taken from all subjects with Baseline Digital Absolute+Axis Goniometer and Baseline Stainless Steel Goniometer $180^{\circ}$. American Orthopaedic Surgeans Academia (AOSA) directives and active range of motion were used. ${ }^{17}$

10 meters walking test: The 10-meter walk test was performed to determine the significance of the treatment's methods on the gait parameter. The hemiplegic patient was instructed to walk at normal speed at the selected 10-meter distance (If the patient was using a walking aid, so the test was carried out with the device used). When the person walked at this selected distance, time account was started when patient put his foot on the starting line and ended when he crossed the finish line. Two measurements were carried on and the best value was recorded as a score. ${ }^{18-20}$

Modified Ashworth Scale (MAS): The evaluation is based on the assessment of the resistance of the clinician on the extremity moving within the normal range of motion. Bohannon and Smith by adding 1+ degree of the Modified Ashworth Scale (MAS) developed. MAS classification revealed the following outcomes: The scale degree ranges from 0 (No raise in muscle tone) to 4 (Affected part rigid in flexion or extension). Also, 1+ indicates few raise in muscle tone, manifested by a catch, followed by minimal resistance of the ROM. ${ }^{21}$

Muscle strength: The Nicholas Manual Muscle Tester (NMMT- model 01165, SI Instruments, U.S.A) which is a kind of the hand held dynamometer (HHD) is a reliable, valid, portable and cost effective assessment method. Also, NMMT provides isometric strength assessment and is easy and practical to use just like HHD. There are many studies related to reliability and validity of NMMT. ${ }^{22-}$ 27

Visual Analogue Scale (VAS): This scale is used to turn into nonnumeric character to numeric values. The scale evaluates the subjective pain intensity. It is a 10-point millimetre numeric scale with 0 representing one pain extreme ("no pain") and 10 representing the other pain extreme ("pain as bad as you can imagine"). Also, the patient is asked to indicate where the patient's condition is on this line by drawing a line or by showing. The length of the distance at the marked point on the line determines the pain level. ${ }^{19,28}$

Electromyographic Biofeedback (EMGBF): The myoelectic signals taking from hemiplegic patients via EMG-BF are transformed to visual and auditory signals and and reported to patients. For this reason, the artificial proprioseption is created by ensuring that the patients are aware of the motor unit activity. With the artificial prorioception, it is aimed to activate the muscle with paresis and to relax the spastic muscle of hemiplegic patient and to regain functional movement pattern. Also, The patient is instructed to activate or decrease the activity of the muscles. Superficial electrodes are usually placed to close and parallel to the muscle origo and insertion. The aim is to provide relaxation and muscle re-education. ${ }^{8,9,15}$ Obtained measurement unit is $\mu \mathrm{V}$ (microvolt).

\section{The ethical aspect of research}

The protocol was approved by the Ethics Committee of Faculty of Medicine of our University (Approval date and number: October 6, 2017;69/17)

\section{Data analysis}

The SPSS 22.0 program was used for statistical analysis. Kolmogorov Smirnov Test was applied for the normal distribution of variables. From these measurements, means, standard deviations, minimum and maximum values were calculated. Also, the Paired 
Samples $\mathrm{T}$ test was used to determine the significance between pre and post intervention. However, some variables demonstrated normal distribution. For this reason, the parametric test was chosen named as Independent Samples T Test. Because of no having normal distribution, Wilcoxon Signed Rank test and Kruskal Wallis test as non-parametric tests were performed. Moreover, the results were assessed at a 95\% confidence interval, with a significance of $p<0.05$, as well as quantitative data were used for the comparison of quantitative data.

\section{Results}

30 hemiplegic patients aged between 40 and 86 years were evaluated. Moreover, the patients were divided into 3 groups by a random method. Moreover, the first group received 30 sessions of Classic Physical Therapy and Rehabilitation (CPTR), the second group received 30 sessions of CPTR and EMS with 15 sessions of Robotic Rehabilitation and the third group received 30 sessions of CPTR and EMS with 15 sessions of EMG-BF. The effects of three different treatment programs on patients' functions were investigated and the results were compared with each other. The significant difference was found in the mean value of age $(p=0.016<0.05$ and height $(p=0.001<0.05)$ between gender. However, there was no significant difference in the mean value of weight $(p=0.699>0.05)$ between gender (Table 1). Additionally, the mean values of age, height and weight were found as $63.50 \pm 10.15$ years, $73.90 \pm 12.88 \mathrm{~kg}$ and $162.10 \pm 7.87 \mathrm{~cm}$ in Group 1, 71.90 \pm 7.75 years, $82.20 \pm 15.33 \mathrm{~kg}$ and $167.10 \pm 10.49 \mathrm{~cm}$ in Group 2, 68.40 \pm 9.06 years, $82.70 \pm 10.69$ $\mathrm{kg}$, and $166.50 \pm 8.81 \mathrm{~cm}$ in Group 3, respectively. Moreover, there was no significant difference in terms of age, height and weight between Groups (Table 2). Also, the increase in the measurement scores of the plantar flexion ROM, dorsi flexion ROM, 10 meter walk test, EMG-BF and NMMT (rightleft) in the post-treatment of applying three different treatment modalities was shown in Table 3 and the results of measurement parameters of groups in the pre and post treatment were given in Table 4 . When the efficiency of the treatment results of the Group 1 was analyzed, there was an increase in dorsi flexion ROM of ten patients. Although, the plantar flexion ROM of the first group increased in 5 patients, and decreased in 1 patient, and there was no change in 4 patients. Dorsi flexion ROM measurement was found as $-12.60^{\circ} \pm 2.79^{\circ}$ and $-6.00^{\circ} \pm 1.09^{\circ}$ in Group 1 in pre-treatment and posttreatment $(\mathrm{p}=0.011)$. Also, according to 10 meter walk test result of the first group, a significant difference was found. There was an improvement in all patients and the walking time was decreased $(\mathrm{p}<0.001)$. Similarly, a positive increase was found in the measurements including EMG-BF and NMMT (right-left side) in 10 patients. In pretreatment, the Modified Ashworth Scale of the three hemiplegic patients was " 0 ", while the same parameter was " 1 " in seven patients (According to MAS, "1" score states that A slight increase in muscle tone, manifested by a catch and release or by minimal resistance at the end of the ROM test when the affected extremity is moved in flexion or extension position). In post-treatment, MAS value was "0" in seven hemiplegic patients (According to MAS, "0" score states that no increase in muscle tone). However, three patients took "1" value. A significant difference was found in MAS score in the pre and post treatment $(\mathrm{p}=0.037)$. According to VAS, there was no change in pain level (In both pre and post treatment, ten patients had no pain; VAS score "0") (Table 3-4).

When the measurements of the second group who received 30 sessions of CPTR and Electrical Muscle Stimulation (EMS) with 15 sessions of Robotic Rehabilitation (RR), were investigated, ten patients showed an increase in dorsi flexion ROM, EMG-BF, NMMT (right and left), 10meter walk test, The mean values of the dorsi flexion ROM were $11.60^{\circ} \pm 9.59^{\circ}$ and $-2.80^{\circ} \pm 8.96^{\circ}$ in Group 2 in pre-intervention and post-intervention, respectively $(\mathrm{p}=0.010)$. Also, the plantar flexion ROM increased in six patients, and decreased in three patients, and there was no change in one patients in post-treatment. However, there was no a significant difference in the same parameter $(p=0.486)$ 
Additionally, nine patients' VAS measurements were " 0 " (no pain), while the same parameter was "2" degrees in one patients in pre-treatment. In post-treatment, nine patients' VAS parameter were "0" (having no pain), whereas one patient declared that he/she had "2" degrees pain in post-treatment. There was no a significant difference between pre and post treatment (p>0.05). MAS value was " 0 " in ten hemiplegic patients (According to MAS, "0" score states that no increase in muscle tone) both in the pre-treatment and post-treatment.

Table 1. The demographic characteristics of the groups by gender

\begin{tabular}{|c|c|c|c|c|c|c|}
\hline \multirow[t]{2}{*}{ Gender } & \multicolumn{3}{|l|}{ Female (17) } & \multicolumn{3}{|l|}{ Male (13) } \\
\hline & Mean \pm SD & Min. & Max. & Mean \pm SD & Min. & Max. \\
\hline$\overline{\text { Age (year) }}$ & $71.47 \pm 7.95$ & 53.00 & 86.00 & $63.31 \pm 9.40$ & 40.00 & 78.00 \\
\hline$p$ value & 0.016 & & & & & \\
\hline Weight (kg) & $80.44 \pm 12.99$ & 54.00 & 112.00 & $78.50 \pm 14.14$ & 55.00 & 98.00 \\
\hline$p$ value & 0.699 & & & & & \\
\hline $\begin{array}{l}\text { Height } \\
p \text { value }\end{array}$ & $\begin{array}{l}160.65 \pm 7.66 \\
\mathbf{0 . 0 0 1}\end{array}$ & 150.00 & 172.00 & $171.23 \pm 7.25$ & 160.00 & 185.00 \\
\hline
\end{tabular}

Table 2. Evaluation results of the demographic characteristics of the groups

\begin{tabular}{llll}
\hline Gender & $\begin{array}{l}\text { Group 1 } \\
\text { Mean } \pm \text { SD } \\
(\text { Min.-Max.) }\end{array}$ & $\begin{array}{l}\text { Group 2 } \\
\text { Mean } \pm \text { SD } \\
(\text { Min.-Max.) }\end{array}$ & $\begin{array}{l}\text { Group 3 } \\
\text { Mean } \pm \text { SD } \\
(\text { Min.-Max })\end{array}$ \\
\hline Age (year) & $63.50 \pm 10.15$ & $71.90 \pm 7.75$ & $68.40 \pm 9.06$ \\
$(50.00-78.00)$ & $(57.00-86.00)$ & \\
$p$ value & $\mathbf{0 . 1 3 3}$ & $82.20 \pm 15.33$ & $82.70 \pm 10.69$ \\
Weight $(\mathbf{k g})$ & $73.90 \pm 12.88$ & $(55.00-112.00)$ & $(60.00-95.00)$ \\
& $(54.00-95.50)$ & & $166.50 \pm 8.81$ \\
$p$ value & $\mathbf{0 . 2 5 9}$ & $167.10 \pm 10.49 \mathrm{~cm}$ & $(153.00-183.00)$ \\
\hline Height $(\mathbf{c m})$ & $162.10 \pm 7.87$ & $(150.00-185.00)$ & \\
\hline
\end{tabular}

Min.: Minimum; Max.: Maximum; SD: Standard deviation

Table 3. The increase in measurement scores in the post-treatment of applying three different treatment modalities

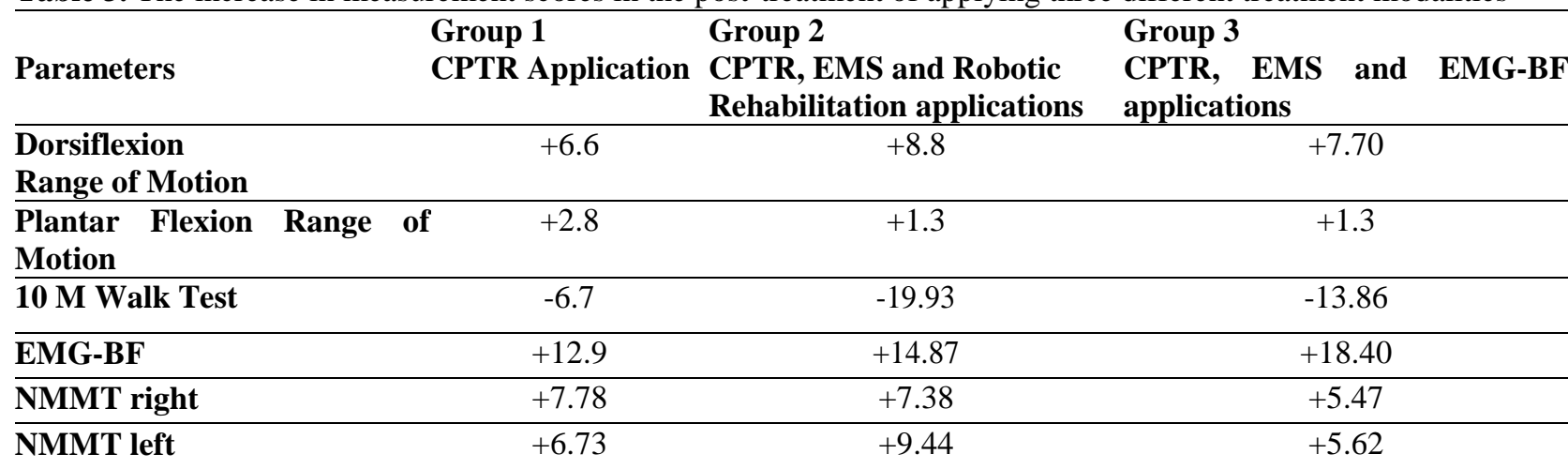

Table 4. The results of measurement parameters by groups at the pre and post intervention

\begin{tabular}{llll}
\hline $\begin{array}{l}\text { Applied Treatment } \\
\text { Modalities }\end{array}$ & Treatment Modalities & $\begin{array}{l}\text { Gender } \\
\text { Mean }\end{array}$ & $\boldsymbol{P}$ \\
\hline Joint ROM Plantar & Group 1 $(\mathrm{n}=10)$ & $49.00 \pm 5.75$ & $\mathbf{0 . 1 2 3}$ \\
Flexion (degree ${ }^{\circ}$ ) & & $51.80 \pm 5.01$ & $\mathbf{0 . 4 8 6}$ \\
& Group 2 $(\mathrm{n}=10)$ & $55.70 \pm 7.60$ & $\mathbf{0 . 4 5 6}$ \\
& \multirow{2}{*}{ Group 3 $(\mathrm{n}=10)$} & $57.00 \pm 4.83$ & $55.70 \pm 7.15$ \\
& & $57.00 \pm 8.49$ & \\
\hline
\end{tabular}




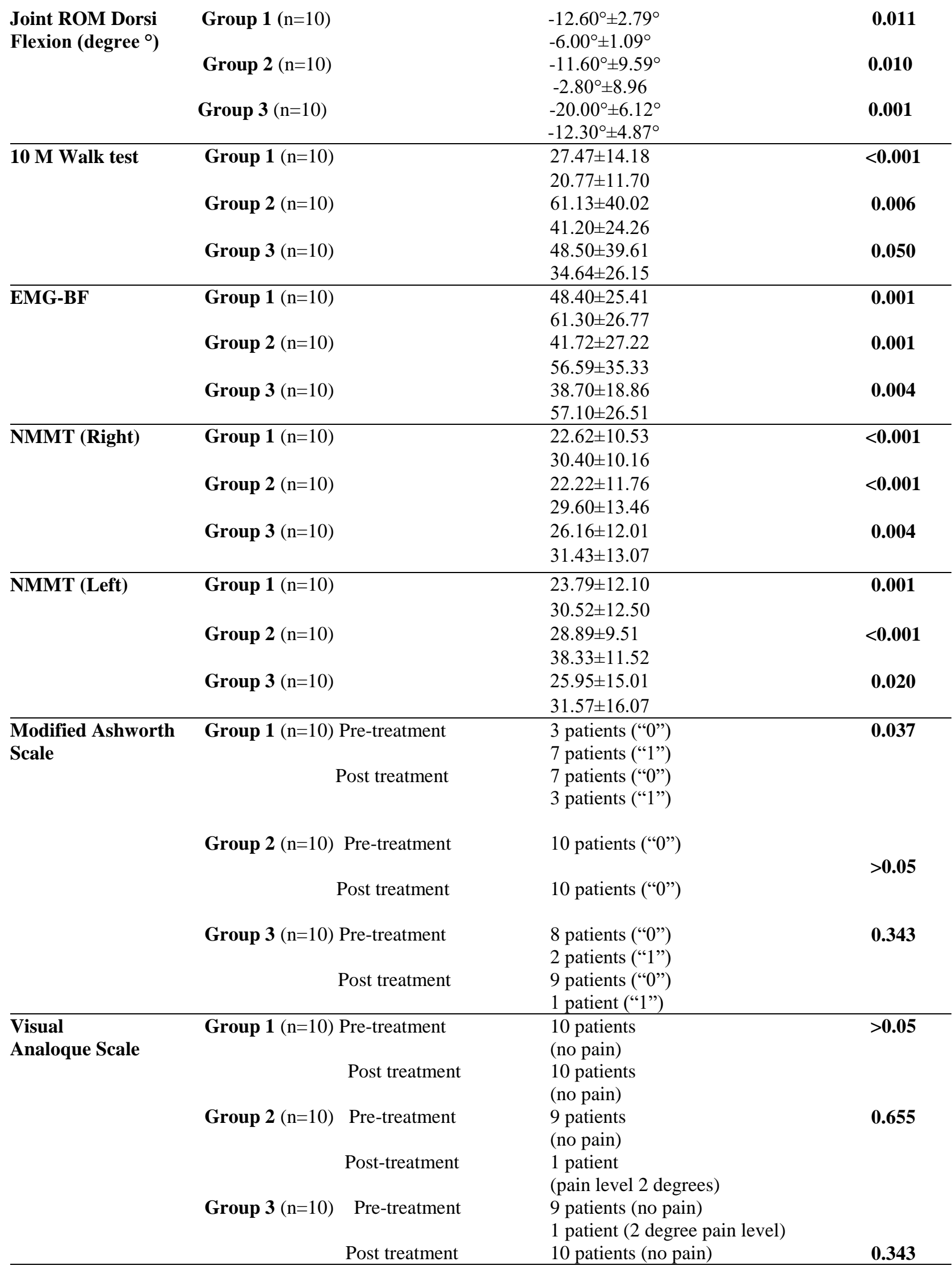

The Classical physical therapy and rehabilitation (40 minutes), Electrical muscle stimulation (30 minutes) and Electromyographic Biofeedback (10 minutes) applications were performed to the third group. The dorsi flexion ROM was found as $20.00^{\circ} \pm 6.12^{\circ}$ and $-12.30^{\circ} \pm 4.87^{\circ}$ in the pre and post intervention, respectively. A significant difference was found in dorsi flexion ROM $(\mathrm{p}=0.001)$, and EMG-BF 
$(\mathrm{p}=0.004)$, NMMT right $(\mathrm{p}=0.004)$ and left $(\mathrm{p}=0.020)$. Also, in the VAS measurement, nine patients had ' 0 ' (no pain) and one patient had ' 2 ' degree pain level in the pre-treatment. In the post-treatment, ten patients had ' 0 ' degree pain level $(\mathrm{p}=0.343)$. In the posttreatment plantar flexion ROM showed a decrease in 2 patients; increase in four patients and remained the same in four patients. Also, there was no a significant difference in Plantar flexion ROM ( $\mathrm{p}=0.456)$. The 10 meter walk time test showed a decrease in nine patients an increase in one patient (patients walked the same distance to a lesser time) $(\mathrm{p}=0.05)$. In Modified Ashworth Scale, eight patients had '0' value (no increase in muscle tone) and two patients had ' 1 ' value (a slight increase in muscle tone, manifested by a catch and release or by minimal resistance at the end of the range of motion when the affected extremity is moved in flexion or extension position) in the pretreatment. Also, nine patients had " 0 " value and one patient had ' 1 ' value in the posttreatment (Table 3-4).

Consequently, when the results of the three different treatment modalities in pre and post treatment were compared, a significant difference was found in all Groups in the measurements including dorsi flexion ROM, EMG-BF and NMMT (right and left). Also, the significant difference in dorsi flexion ROM was higher in Group 3 than Group 2 and Group 1, respectively. Additionally, there was no a significant difference in plantar flexion ROM in all groups; whereas, there was an increase in the same parameter in three groups. Moreover, the significance of the 10 meter walk test was higher in Group 1 than Group 2 and Group 3. There was a significant difference in MAS parameter in Group $1 \quad(p=0.037)$, while a significant difference was no found in Group 3 $(\mathrm{p}=0.343)$. We can say that the MAS score of Group 2 was the same in pre-treatment and post-treatment ("0"; no increase in muscle tone). Already, the patients have had no spasticity (Table 4).

According to Table 3, the most increase in the dorsi flexion ROM, $10 \mathrm{~m}$ walk test and NMMT (left) was obtained in Group 2:
Classical physical therapy and rehabilitation (40 minutes), Electrical muscle stimulation (30 minutes) and Robotic Rehabilitation (15 minutes). Also, in Group 1:Classical physical therapy and rehabilitation (40 minutes), increase in the plantar flexion ROM was higher than Group 2 and Group 3. Additionally, the EMG-BF value is the higher in Group 3: Classical physical therapy and rehabilitation (40 minutes), Electrical muscle stimulation (30 minutes) and EMG-BF (15 minutes). An increase of 12.9 was made a progress in EMG-BF parameter of Group 1 taking 30 sessions of CPTR. Although, an increase of 14.87 in EMG-BF parameter of Group 2 taking 30 sessions of CPTR and EMS with 15 sessions of RR, and an increase of 18.40 in Group 3 taking 30 sessions CPTR and EMS with 15 sessions EMG-BF were seen. In addition, NMMT (right and left side) measurement results were lower in Group 3 than Group 1 and Group 2. (Table 3).

\section{Discussion}

This study was conducted to put forward a comparison between three different rehabilitation's treatment modalities. Moreover, their advantageous and limitations were shown as well. The study was a homogeneous distribution of groups, the evaluated data revealed objectively, the results that showed the most effective treatment. Stroke was seen frequently around the world. Subjects having stroke needs to help for mobility, self-care, and household activities. ${ }^{2,3,29}$. Stroke is the third most prevalent reason of death followed by cancer and heart diseases. The most important undesired result is a hemiparetic gait. The gait restrains activity, rise the falling hazard, broken, the risk of diabetes and heart disease, depression, cognitive inability, decrease in activities of daily living, subsequent stroke, and death. Approximately, $72 \%$ of stroke patients are faced with lower extremity weakness. ${ }^{3,8,16,20,30}$ The most frequent symptom is motor deficit. Stroke also causes impaired motor function. ${ }^{6,30-32}$. Also, ankle muscles are more badly influenced than the other muscles. ${ }^{20}$ The weakness may originated from the size of low muscle fibre and motor unit, attenuated firing rate, raised 
fatigue. Additionally, muscle weakness results from decreased gait velocity and strength. ${ }^{13,33,34}$ Force control insufficiency in the tibialis anterior muscle (mTA), such as weakness, delayed or decreased recruitment, and reduced motor cortical control, is characterized by an inability to adequately dorsiflexion the ankle during functional tasks such as moving from sitting to standing, stand-pivot-sit transfer, standing with balance perturbation, curb or stair climbing, and walking. ${ }^{20}$ Yang et al's study showed that 30 minute task oriented progressive resistance strength training three times a week for four weeks can improve lower extremity muscle strength, motor learning (the development of neuromotor patterns of co-ordination between agonist and antagonist muscles) in subjects having chronic stroke and could carry over into improvement in functional abilities. Also, the dorsi flexors were measured as 48.3 pound and 30.3 pound in strong and paretic sides, in subjects having stroke received task oriented progressive resistance strength respectively. The same measurements were found as 58.5 pound and 41.2 pound in strong and paretic sides of subjects having stroke received task oriented progressive resistance strength respectively. The change scores of dorsi flex or muscle strength training was 10.3 pound and 11.0 pound in subjects having stroke received task oriented progressive resistance strength. The results of six minute walking test were 352.3 meter (pretest) and 392.8 meter (posttest) in subjects having stroke received task oriented progressive resistance strength. The change score between pre and post test was found as 40.6 meter in subjects having stroke received task oriented progressive resistance strength. ${ }^{34}$ TA muscle exercise training with task-oriented training plays an important role in stroke rehabilitation; however, it is difficult to obtain exercise training for the TA muscle because of the main weakness and insufficient muscle recruitment in patients having stroke..$^{20,32}$ Conversely, the effects on increase in strength and improving lower limb motor function of TA muscle exercise training is lacking $16,20,21,31$ and there is few studies about EMG$\mathrm{BF}$ in combination with standard physical therapy leading to increase in TA muscle strength.

Also, Tsaih et al reported that EMG-BF was an effective method in stroke treatment to help muscle training and enhance motor learning by supplying visual or audio feedback of muscle activation, and task oriented and motor learning principles using EMG-BF (EMG-BF assisted TA exercises during walking, and balance related tasks such as standing with toes up, weight shifting, stepping, going up/down the stairs, or walking according to subjects' abilities) enhanced strength and balance in subjects having stroke and might be used as alternative treatment model. In the same study, the strength of the affected TA muscle using handheld dynamometer and six minute walking test parameters were measured as $102.01 \mathrm{NT}$ and 198.08 meter in baseline and 137.96 NT and 242.62 meter at 6 weeks posttraining. Both TA muscle strength and walking speed results were significantly higher in both EMG-BF groups at 2 weeks posttraining and 6 weeks posttraining than at baseline. Repeated measures explained significant interaction effects between testing sessions and groups for the strength of the affected mTA. The muscle strength effects for TA continued to 6 weeks posttraining. For this reason, the EMG$\mathrm{BF}$ training was effective and feasible for subjects having impaired mTA muscle strength and might to be advised for stroke subjects with mTA force insufficiency. ${ }^{20}$ In stroke rehabilitation approaches, conventional walking therapy, such as the Bobath training, proprioceptive neuromuscular facilitation, professional-assisted walking, and the usage of braces or other devices are used mostly. $8,9,14-16$

Physical activity is defined as any bodily movements produced by the skeletal muscles. This result form rise in energy expenditure. Physical activity may influence many functional activities and health status in this type patients. Subject with patients have low physical activity levels and spend more time in low-energy expenditure activities. In a study performed with 22 adults having stroke who have physical inactivity and sedentary, warm-up and cool-down treadmill walking, 
followed by $1 / 2$ hours of aerobic treadmill training was performed. Also, it was reported that decreased physical activity was associated with risk of cardiovascular disease, the treatment method might provide to develop functionality and condition of patients. ${ }^{29}$ In a study performed with 43 subjects with stroke with by Stuart et al, Adaptive Physical Activity (APA) exercise program comprising gait, enduance, and balance training was practiced. The intervention was 1 hour, 3 times a week, in 5 community locations. APA-Stroke has proven to be safe, feasible, and effective for stroke survivors in home and community settings in three separate trials, conducted in 2 countries featuring very different involvement of the health systems. The studies provide keeping up evidence that, with suitable visualization and exercises. Thus for, stroke patients may provide functional gains. Also, significant improvement was recorded in walking speed. ${ }^{3}$ Robot-assisted gait training (RAGT) has been used since 1980 to provide help subjects with movement restriction in especially neurological disorders. Treatment by RAGT provides some advantages, such as training duration, more symmetrical gait patterns, symmetrical muscle activity pattern. ${ }^{7,8,35}$ Stroke patients showed improvement in gait velocity, functionality, and motor functions after treatment. ${ }^{8,35,36}$ In another study, three times of physiotherapy per week and were prescribed home exercises. Each group took two times conventional physiotherapy and 1 session gait training. The treatment continued with 60 minutes. Also, the rehabilitation formed by stretching and strengthening, balance training, postural stability control, sensory techniques, and functional daily activities. Especially, clear improvement was seen in balance, functional independence in daily living activities. ${ }^{7}$ In addition, in a study performed by Yeung et al., nineteen chronic stroke patients having motor impairment at ankle participated in 20-session robot-assisted gait training for about five weeks, with 30min over-ground walking and stair ambulation practices. After 20 -session robotassisted gait training with ankle dorsiflexion assistance, the active ankle assistance in Group 2 helps to changes in gait pattern with improved gait independency, motor recovery, walking speed, and greater confidence in affected side loading response with heel strike instead of flat foot touch down at initial contact. Also, Robot-assisted gait training with ankle dorsiflexion can develop gait independency and provide to stroke patients developing confidence in weight acceptance. ${ }^{37}$ In a study of Bogotaj's et al., using Multichannel Functional Electrical Stimulation (MFES) adjunc to conventional therapy in 20 patients with severe hemiplegia, group using MFES followed by conventional therapy showed achievement in motor learning in a less time. In the same study, it was also shown that the combined practices provided to return of the patient's to daily life activities faster. ${ }^{38}$ In another study performed by Bradley et al., with twenty one patients (12 patients receiving EMG-BF and physiotherapy treatments and nine subjects receiving only physiotherapy) three times a week for six weeks, an improvement in physical scores was found in active movement, mobility and daily living activities. However there was no significant difference in the rate of improvement between two groups. ${ }^{39}$ Various treatment modalities are applied alone or in combination in gait rehabilitation of hemiplegic patients in the literature and practice. However, there are not enough studies comparing the effectiveness of new modalities. In addition, although there are studies on the prevention of low foot in patients with post-stroke hemiplegia, it is seen that there is no consensus on the effect of combined applications on mTA spasticity.

For this reason, it was aimed to compare the effectiveness of exercise, EMS, EMG-BF and RR in the tibialis anterior muscle activation of hemiplegic patients and to investigate the functional changes provided by these applications. This was the first study due to rehabilitation protocols which are applied to Group 2 and Group 3. Since the NMMT and EMG-BF measurements used to demonstrate the effectiveness of treatment in hemiplegia patients were used for the tibialis anterior muscle force. In the post treatment mTA force of Group 1 and 2 (NMMT, and EMG-BF) was more signifant than Group 3. 
As a result, there were the positive effects of three different treatment methods on ROM, NMMT force measurements and EMG-BF, walking time, spasticity. Also, three treatment modalities contributed to recovery level of hemiplegic patients in different levels.

\section{Limitation of the Study}

There are some limitations about this study. The major limitation was the scarce of follow-up studies (3 month, 6 month later). In order to reveal the effectiveness level of the treatment program applied, future longitudinal studies are needed. This study was conducted in a narrow scope. It is thought that further studies to be carried out in long duration and with the further hemiplegic subjects may have more productive results in terms of revealing the effects on patients' development.

We can suggest the follow-up studies after 3 or 6 months. Successful results can be obtained by extending the rehabilitation treatments lasting life-long and active and willingly

\section{Ethics Committee Approval}

The protocol was approved by the Ethics Committee of our university' Faculty of Medicine (Approval date and number: October 6, 2017; 69/17).

\section{Informed Consent}

Requirement for informed consent was waived by the hospital ethics committee.

\section{Author Contributions}

Conception-M.A., A.H.Y., S.P.; DesignA.H.Y., M.A., S.P.; Supervision-A..H.Y., S.P.; Materials- M.A., S.P., E.İ.I.; Data Collection and/or Processing-M.A., S.P., E.İ.I.; Analysis and/or Interpretation-A.H.Y., S.P., M.A., E.I.I; Literature review- S.P., M.A.; Writer-M.A., S.P.; Critical ReviewA.H.Y., S.P., M.A., E.İ.I.

\section{Conflict of Interest}

No conflict of interest was declared by the authors.

\section{Financial Disclosure}

The authors declared that this study has received no financial support.

\section{Acknowledgement}

The authors would like to thank to Prof. Dr. Ahmet Hilmi Yücel for his advice and comments.

\section{Peer-review}

Externally peer-reviewed.

\section{References}

1. Hankey GJ. Stroke. Lancet. 2017; 389: 641-654.

2. D'iaz I, Gil JJ, S'anchez E. Lower-limb robotic rehabilitation: Literature review and challenges. Hindawi Publishing Corporation Journal of Robotics. 2011;1-12.

3. Stuart M, Dromerick AW, Macko R, et al. Adaptive physical activity for stroke: An early-stage randomized controlled trial in the United States. Neurorehabil Neural Repair. 2019 August; 33(8): 668-680.

4. Marganska VK, Blanco J, Campen K, et al. Three-dimensional, task-specifi c robot therapy of the arm after stroke: a multicentre, parallel-group randomised tria. Lancet Neurol,2014;13(2):159-166.

5. Serra MC, Accardi CJ, Ma C, et al. Metabolomics of Aerobic Exercise in Chronic Stroke Survivors: A Pilot Study. J Stroke Cerebrovasc. Dis., 2019; 28 (12):1-9.

6. Etoh S, Noma T, Miyata R, Shimodozono M. Effects of repetitive facilitative exercise on spasticity in the upper paretic limb after subacute stroke. J Stroke Cerebrovasc Dis., 2018; 27 (10): 2863-2368.

7. Swinnen E, Beckwée D, Meeusen R, Baeyens JP, Kerckhofs E. Does robot-assisted gait rehabilitation improve balance in stroke patients? A systematic review. Top Stroke Rehabil. 2014; 21(2): 87-100.

8. Belas dos Santos M, Barros de Oliveira C, Dos Santos A, Pires CG, Dylewski V, Arida RM. A Comparative Study of Conventional Physiotherapy versus Robot-Assisted Gait Training Associated to Physiotherapy in Individuals with Ataxia after Stroke. Behavioural Neurology 2018:1-6.

9. Bezerre Dos Santos Cardozo L, Moreira MC, Monteiro UM, Salvetti A, Paula A, Rodrigues MC. Spasticity reduction through EMG Biofeedback relaxation in post-stroke patients: a pilot study. Montreal QC; International Conference on Virtual Rehabilitation, 2017; 1-3.

10. Baricich A, Picelli A, Carda S, et al. Electrical stimulation of antagonist muscles after botulinum toxin type A for post-stroke spastic equinus foot. A randomized single-blind pilot study. Ann Phys Rehabil Med. 2019; 62: 214-19.

11. Kaji R, Osako Y, Suyama K, Maeda T. Botulinum toxin type A in post-stroke lower limbspasticity: a multicenter, double-blind, placebo-controlled trial. J Neurol. 2010; 257 (8): 1330-1337.

12. Burbaud P, Wiart L, Dubos JL, et al. A randomised double blind plasebo controlled trial ofbotulinum toxin in the treatment of spastic foot in hemiparetic patients. J Neurol Neurosurg Psychiatry. 1996; 61: 265-269.

13. Van Gelder LMA, Barnes A, Wheat JS, Heller BW. The use of biofeedback for gait retraining: A mapping review. Clin Biomech. 2018;59:159-166.

14. Bakhtiary AH, Fatemy E. Does electrical stimulation reduce spasticity after stroke? A randomized controlled study. Clin Rehabil, 2008; 22: 418-425.

15. Uzunca K. İnmeli Hastalarda EMG Biofeedback Kullanımı. Tip Rehab Derg, 2007;53(Özel say1 1):26-29.

16. Hammami N, Coroian FO, Julia M, et al. Isokinetic muscle strengthening after acquired cerebral damage: a literature review. Ann Phys Rehabil Med. 2012; 55 (4):279-291.

17. Otman AS, Köse N. Tedavi Hareketlerinde Temel Değerlendirme Prensipleri. 10th ed. Ankara: Pegem Akademi; 2016;1-202.

18. Shubert TE, Schrodt LA, Mercer VS, Busby Whitehead J, Giuliani CA. Are Scores on Balance Screening Tests Associated with Mobility in Older Adults?. J Geriatr Phys Ther, 2006;29(1):35-39.

19. Polat SÖ, Yücel AH, Ince G. The effects of an eight-week multi-model sport activity home programme on function of 
children with cerebral palsy. Biomed Hum Kinet. 2020;12, 105114.

20. Tsaih PL, Chiu MJ, Luh JJ, Yang YR, Lin JJ, Hu MH. Practice Variability Combined with Task-Oriented Electromyographic Biofeedback Enhances Strength and Balance in People with Chronic Stroke. Hindawi Behav Neurol. 2018;1-9.

21. Bohannon RW, Smith MB. Interrater reliability of a modified Ashworth scale of muscle spasticity. Phys ther. 1987;67(2): 206-207.

22. Krause DA, Neuger MD, Lambert KA, Johnson AE, Devinny HA, Hollman JH. Effects of examiner strength on reliability of hip strength testing using a handheld dynamometer. J Sport Rehabil. 2014; 23:56-64.

23. Arnold CM, Warkentin KD, Chilibeck PD, Magnus CRA. The reliability and validity of handheld dynamometry for the measurement of lower extremity muscle strength in older adults. J Strength Cond Res. 2010; 24(3):815-824.

24. Bohannon RW. Reference values for extremity muscle strength obtained by hand held dynamometry from adults aged 20 to 79 years. Arch Phys Med Rehabil. 1997;78:26-32.

25. Moss CL, Wright PT. Comparison of three methods of assessing muscle strength and imbalance ratios of the knee. $J$ Athl Train. 1993; 28(1): 55-58.

26. Dunn JC, Iversen MD. Interrater reliability of knee muscle forces obtained by hand-held dynamometer from elderly subjects with degenerative back pain. J Geriatr Phys Ther. 2003; 26: 3(3): 23-29.

27. Aras Ö, Aras B, Yilmaz I, Kabay SC. Parkinson'lu olgularda kas kuvvet değerlendirmelerinin test-tekrar test güvenilirliği. TUBAV Bilim Dergisi. 2009; 2(1): 122-125.

28. Klimek L, Bergmann KC, Biedermann T, et al. Visual analogue scales (VAS): Measuring instruments for the documentation of symptoms and therapy monitoring in cases of allergic rhinitis in everyday health care. Allergo J Int. 2017;26: 16-24.

29. Aguiar LT, Nadeau S, Britto RR, et al. Effects of aerobic training on physical activity in people with stroke: protocol for a randomized controlled trial. Trials. 2018;19 (1):446-453.

30. Lawrence ES, Coshall C, Dundas R, et al. Estimates of the prevalence of acute stroke impairments and disability in a multiethnic population. Stroke. 2001;32:1279-84.

31. Bohannon RW. Muscle strength and muscle training after stroke. J Rehabil Med. 2017;39 (1):14-20.

32. Dragert K, Zehr EP. High-intensity unilateral dorsi flexor resistance training results in bilateral neuromuscular plasticity after stroke. Exp Brain Res. 2013;225(1):93-104.

33. Candan SA İnmeli hastalarda modifiye kıstlayarak zorlayıcı hareket tedavisinin alt ekstremite fonksiyonları, denge, ambulasyon ve yaşam kalitesi üzerine etkileri [Dissertation].Ankara, Turkey: Hacettepe University;2015.

34. Yang YR, Wang RY, Lin KH, Chu MY, Chan RC. Taskoriented progressive resistance strength training improves muscle strength and functional performance in individuals with stroke. Clin Rehabil. 2006; 20: 860-870.

35. Krishnan C, Kotsapouikis D, Dhaher YY, Rymer WZ. Reducing robotic guidance during robot-assisted gait training improves gait function: a case report on a stroke survivor. Arch Phys Med Rehabil. 2013; 94 (6):1202-1206.

36. Tefertiller C, Pharo B, Evans N, Winchester P. Effica of rehabilitation robotics for walking training in neurological disorders: a review. J Rehabil Res Dev. 2011;48 (4): 387-416.

37. Yeung LF, Ockenfeld C, Pang MK, Wai HW, Soo OY, Li SW, Tong KY. Randomized controlled trial of robot assisted gait training with dorsiflexion assistance on chronic stroke patients wearing ankle-foot-orthosis. J Neuroeng Rehabil. 2018 Jun; 19;15(1):51-62.

38. Bogataj U, Gros N, KiJajic M, Acimovic R, Malezic M. The rehabilitation of gait in patients with hemiplegia: A Comparison Between Conventional Therapy and multichannel Functional Electrical Stimulation Therapy. Phys Ther. 1995;75(6):490-502

39. Bradley L, Hart BB, Mandana S, Flowers K, Riches M, Sanderson P. Electromyographic biofeedback for gait training after stroke. Clin Rehabil. 1998;12:11-22. 